\title{
Diffusion of Boron in Alpha Iron
}

\author{
by Paul E. Busby and Cyril Wells
}

$\mathbf{F}$ URTHER study of data used in determinations of 1 -rates of diffusion of boron in austenite and 2 -solubilities of boron in the $\alpha$ and $\gamma$ phases of iron and steel $^{1}$ has provided an equation for the diffusion of boron in $\alpha$ iron. In brief, the previously published data were accumulated from the results of deboronizing (and decarburizing) experiments carried out in the range of $700^{\circ}$ to $1300^{\circ} \mathrm{C}$. Diffusion coefficients $\left(D_{\gamma}\right)$ for boron in austenite were calculated using the Grube solution of Fick's law. However, only solubility values were estimated from the discontinuous concentration-penetration curves, Fig. 1, which are characteristic of diffusion in two phases.

Dr. Carl Wagner ${ }^{2}$ has recently provided a solution for calculating $D$ values from penetration curves of this type as follows:

$$
\frac{C_{\mathrm{II}, \mathrm{I}}-C_{s}}{C_{0}-C_{\mathrm{II}, \mathrm{I}}}=\sqrt{ } \pi \gamma e^{\gamma 2} \operatorname{erf}(\gamma)
$$

and

$$
D=\frac{\xi^{2}}{4 \gamma^{2} t}
$$

where $C_{\mathrm{II}, \mathrm{I}}, C_{s}, C_{0}$, and $\xi$ have the values shown in Fig. 1. $D$ is the diffusion coefficient, sq $\mathrm{cm}$ per sec; $t$ is time of deboronizing anneal, sec; and $\gamma$ is a dimensionless parameter.

For a given diffusion experiment, the value of $\gamma$ can be readily obtained by graphical solution from a plot of $\gamma$ vs the right-hand part of Eq. 1. D may then be evaluated from Eq. 2 .

The application of this solution to previously reported results, ${ }^{1}$ of which excerpts are given in Table I, permits the calculation of diffusion coefficients for boron in $\alpha$ iron.

On the basis of these meager data, it is tentatively concluded that the diffusion of boron in $\alpha$ may be represented by the equation

$$
D_{a}=10^{6} e^{-62,000 / R T}
$$

where $R$ is the gas constant, cal $\times{ }^{\circ} \mathrm{C}^{-1} \times \mathrm{mol}^{-1}$; and $T$ is the absolute temperature, ${ }^{\circ} \mathrm{K}$. Although the frequency factor, $10^{6} \mathrm{sq} \mathrm{cm}$ per sec, is admittedly several orders of magnitude higher than expected, the value of $Q, 62,000$ cal per mol, appears reasonable and is, in fact, very similar to that for the selfdiffusion of iron. It is pertinent to mention at this point that the value of $Q$ obtained for the diffusion of boron in austenite by means of the Wagner solution is 19,000 cal per mol and is in excellent agreement with the value previously reported $^{1}$ in the equation

$$
D_{\gamma}=2 \times 10^{-3} e^{-21,000 / R T}
$$

which was determined by the application of the Grube solution to other data. The fact that determined constants $A$ and $Q$ in the equation $D_{\gamma}=A e^{-Q / R T}$ were practically the same, independent of whether the Wagner or Grube solutions were used in determinations of $D$ values, strengthened the

P. E. BUSBY is Research Metallurgical Engineer, and C. WELLS, Member AIME, is Principal Research Metallurgical Engineer, Metals Research Laboratory, Carnegie Institute of Technology, Pittsburgh.

TN 222E. Manuscript, Oct. 16, 1953.

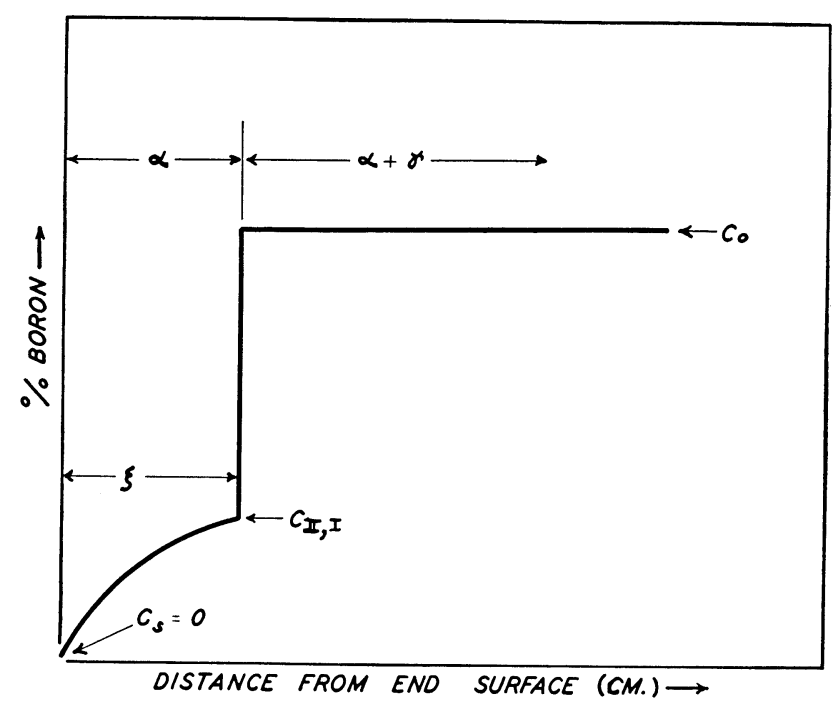

\begin{tabular}{|c|c|c|c|c|c|}
\hline $\begin{array}{l}\text { Test } \\
\text { No. }\end{array}$ & $\underset{\mathbf{H r}}{\text { Time, }}$ & $\begin{array}{l}\text { Tempera- } \\
\text { ture, }{ }^{\circ} \mathbf{C}\end{array}$ & $\begin{array}{l}\text { Solu- } \\
\text { bility in } \alpha, \\
\text { Pet B }\end{array}$ & $\begin{array}{l}\xi, \\
\mathbf{m}\end{array}$ & $\begin{array}{l}D_{a \times 10^{8}} \\
\text { SqCM } \\
\text { per Sec }\end{array}$ \\
\hline $\begin{array}{l}11 \\
12 \\
13 \\
14\end{array}$ & $\begin{array}{l}94 \\
97.8 \\
17.8 \\
17.1\end{array}$ & $\begin{array}{l}700 \\
751 \\
835 \\
850\end{array}$ & $\begin{array}{r}0.0003 \\
0.0006 \\
0.0018 \\
<0.0035\end{array}$ & $\begin{array}{l}0.03 \\
0.08 \\
0.10 \\
0.035\end{array}$ & $\begin{array}{r}1.4 \\
4.4 \\
63 \\
-\end{array}$ \\
\hline
\end{tabular}

Fig. 1-Schematic concentration-penetration curve representing diffusion of boron in two phases.

Table I. Summary of Diffusion Experiments in the $\alpha$ Phase

authors' belief that the computed values of $D_{a}$ (Table I) using the Wagner solution are reliable.

The relative values in Eqs. 3 and 4 for the diffusion of boron in the $\alpha$ and $\gamma$ phases, respectively, suggest that boron forms a substitutional solid solution in $\alpha$ iron and an interstitial solid solution in $\gamma$ iron. The same tentative conclusion has been reached by McBride et al. $^{3}$ on the basis of relative solubilities, atom diameter, and the size of the interstitial hole in $\alpha$ and $\gamma$ iron.

In connection with the data for test 14 listed in Table I, it is of interest to calculate the solubility of boron in $\alpha$ iron using the $D$ value given by Eq. 3. As might be anticipated from the small movement of the interface in test 14, proper substitutions in Eqs. 2 and 1 give a low value, approximately 0.0004 pct $\mathrm{B}$, at $850^{\circ} \mathrm{C}$. Apparently at $835^{\circ} \mathrm{C}$ (test 13) it is possible to obtain 0.0018 pet $\mathrm{B}$, and at $850^{\circ} \mathrm{C}$ only 0.0004 pct $B$ into solution in the $\alpha$ phase before a second phase appears. These observations are consistent with the Fe-B constitution diagram proposed by McBride, Spretnak, and Speiser. ${ }^{3}$

\section{References}

${ }^{1}$ P. E. Busby, M. E. Warga, and C. Wells: Diffusion and Solubility of Boron in Iron and Steel. Trans. AIME (1953) 197, p. 1463; Journal of Metals (November 1953).

${ }^{2}$ W. Jost: Diffusion in Solids, Liquids, Gases. pp. 69-71. New York. Academic Press Inc.

${ }^{3}$ C. C. McBride, J. W. Spretnak, and R. Speiser: A

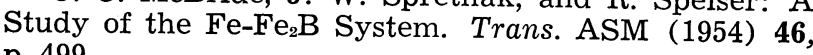
p. 499. 